\title{
Dampak dari Parameter Variasi Koneksi, Node dan Kecepatan Node Terhadap Delay pada Routing Protocol AODV dan BATMAN Jaringan MANET
}

\author{
${ }^{1}$ Dodon T. Nugrahadi, ${ }^{2}$ M. Reza Faisal, ${ }^{3}$ Liling Triyasmono, ${ }^{4}$ Muhammad Janawi, \\ ${ }_{1,2,4}$ Prodi Ilmu Komputer, FMIPA, Universitas Lambung Mangkurat \\ ${ }^{3}$ Prodi Farmasi, FMIPA, Universitas Lambung Mangkurat \\ Jalan Jl. Brigjen H. Hasan Basri, Kayu Tangi, Banjarmasin \\ e-mail : ${ }^{1}$ dodonturianto@ulm.ac.id, ${ }^{2}$ reza.faisal@ulm.ac.id, ${ }^{3}$ liling2382imeru@ gmail.com \\ ${ }^{4}$ muhammad.janawi99@gmail.com
}

\begin{abstract}
Mobile ad-hoc Network (MANET) is a multihop wireless network that a many collection of mobile nodes that are dynamic. MANET each node on the network have the same position, so it needs the appropriate routing protocol, to support the exchange of data to be optimal. In this study, the routing protocol to be tested is AODV and BATMAN based scenario increasing the number of connections, nodes and speed. Simulation parameter scenarios is number connection 1 UDP, 2 UDP, 3 UDP, and number of node 25 node, 50 node, 100 node, and then number node speed 20 $\mathrm{m} / \mathrm{s}, 50 \mathrm{~m} / \mathrm{s}$. in this AODV routing protocol will establish a rute from the source node to the destination only if there is a request from the source node. BATMAN routing protocols, all decisions and information disseminated throughout the node and will regularly update on each node. The performance parameters to be measured such as delay by using OMNET ++4.6 . Output of simulation will analysis with two way anova and multivariate to know correlation between variation scenario impact to delay. The results obtained in this study AODV and BATMAN have their respective advantages, analisys with two-way anova show that both AODV and BATMAN get the impact of the scenario from incrising the number of connections, the number of nodes and the number of nodes speed with a p-value of $0.012212(<0.05)$ with two-way anova. From all scenarios, the number of UDP connections has the greatest impact, from UDP 1, UDP 2 and UDP 3. Followed by the number of speed 50 and node 100. So it can be concluded that the connection has an effect on increasing delay. The increasing number of speed and nodes can contribute to an increase in delay if number of nodes above 100 and speed above 50. With multivariate analysis, the BATMAN protocol had the most impact on the delay under the scenario then AODV.
\end{abstract}

Keywords: MANET, AODV, BATMAN, Throughput, Delay, Paket Loss, Overhead Ratio, OMNET++

\section{PENDAHULUAN}

Penggunaan jaringan nirkabel (wireless) terus meningkat penggunaannya dibandingkan jaringan kabel. Salah satu teknologi jaringan nirkabel yaitu jaringan ad-hoc. Jaringan ad-hoc salah satu solusi bagi perangkat bergerak (mobile) seperti laptop, tablet, smartphone, dan sebagainya untuk berkomunikasi satu sama lain tanpa dukungan infrastruktur jaringan nirkabel yang umum digunakan sebagai pendukung transmisi data [1].

Jaringan ad-hoc dapat berjalan tanpa harus menggunakan insfrastruktur yang ada, seperti base station (acces point) atau sarana pendukung transmisi data lainnya. tiap-tiap peangkat yang berada pada jaringan ini disebut node. Setiap node akan berkomunikasi dengan node lainnya dalam satu jaringan tersebut. Jaringan ad-hoc juga mempunyai infrastruktur node jaringan yang tidak permanen. Jaringan ini terdiri atas node yang bersifat mobile dengan satu atau lebih antar muka pada setiap node. setiap node pada jaringan ad-hoc diharapkan mampu menjaga performa trafik paket data dalam jaringan yang disebabkan mobilitas node yaitu dengan cara rekonfigurasi jaringan [7].

Teknologi jaringan ad-hoc atau Mobile ad-hoc Network (MANET) merupakan sekumpulan titik node yang menggunakan antarmuka jaringan nirkabel untuk dapat melakukan pertukaran informasi antar node. Setiap node dapat dijadikan suatu host ataupun router yang mampu meneruskan paket data menuju node berikutnya. Pada kondisi ini protokol routing diperlukan dalam jaringan untuk menunjang proses kirim dan terima paket data antar node. Protokol routing memiliki kemampuan untuk melewati dan meneruskan ke banyak node (multihop), agar setiap node dapat berkomunikasi 
dengan node yang berada diluar jangkauannya [5]. Masalah yang muncul adalah menentukan penggunaan jalur efisien dalam pengiriman paket data dari sumber ke tujuan. Oleh karena itu diperlukan protokol routing yang mampu memenuhi kebutuhan jaringan tersebut untuk dapat memberikan jalur routing terbaik dan secara optimal.

Beberapa penelitian sebelumnya yang pernah dilakukan antara lain yaitu "Performance of MANET Routing Protocols considering Impact of Node Density under Different Traffic Patterns" [4]. Pada penelitian ini membandingkan kinerja protokol routing proaktif (DSDV) dan reaktif (AODV \& DSR) dengan pola lalu lintas CBR dan TCP, parameter kinerja protokol routing yang diukur adalah paket delivery ratio, average end-to-end delay, normalized routing load, dan average jitter pada sejumlah sumber dan node yang bervariasi, pada penelitian ini dihasilkan routing AODV tampil lebih unggul saat beban lalu lintas dan kepadatan node tinggi. Adapun penelitian lainnya yaitu " $A$ Comparative Study of B.A.T.M.A.N. and OLSR Routing Protocols for MANETs" [6]. Protokol ini dianalisis berupa pengaruh node (jaringan), panjang paket (lalu lintas) dan mobilitas untuk memeriksa kinerja kedua protokol, pada penelitian ini dihasilkan bahwa BATMAN lebih unggul dari pada OLSR dalam hal throughput, waktu delay dan beban CPU nya yang lebih rendah. Berdasarkan penelitian tersebut bahwa protokol BATMAN dan AODV merupakan protokol yang unggul baik reaktif dan proaktif. Penelitian yang lain yaitu "Impact of Node Density on Node Connectivity in MANET Routing Protocols" [2], dilakukan pengukuran parameter konektivitas node dan kepadatan node pada protokol reaktif dan proaktif menunjukkan peningkatan overhead. Jumlah paket routing menunjukkan menurun dengan peningkatan kepadatan Node.

Bertolak pada hasil dan penelitian sebelumnya penelitian ini akan membandingkan dua routing protocol yang memiliki keunggulan untuk digunakan di jaringan MANET yaitu routing protocol reaktif AODV dan proaktif BATMAN dengan skenario yang berbeda dari penelitian sebelumnya yaitu skenario variasi jumlah koneksi, kepadatan node, dan kecepatan node. variasi parameter yang di ambil adalah delay. Berdasarkan skenario tersebut untuk melihat keterikatannya dengan delay.

\section{STUDI LITERATUR}

\subsection{AODV}

AODV (Ad-hoc On-demand Distance Vector) adalah protokol routing yang bersifat reaktif yaitu protokol ini bekerja saat ada permintaan dari source node untuk mengumpulkan informasi jalurjalur yang dapat digunakan untuk mengirimkan pesan ke node tujuan. AODV akan berusaha untuk menemukan jalur yang tidak ada loop dan menemukan jalur terpendek untuk menuju node tujuan sesuai tabel routing yang dibuat [1].

Pesan dalam protokol routing AODV terbagi menjadi 3 yaitu RREQ (Route Request), RREP (Route Reply) dan RRER (Route Error). RREQ dan RREP merupakan route pencarian jalur sedangkan RRER merupakan route maintenance.

1. Proses komunikasi pada protokol routing AODV dimulai pada saat ada permintaan dari source node atau node tujuan dengan cara pesan RREQ akan disebarkan atau di broadcast keseluruh node yang mampu dijangkaunya jika node antara tidak mengetahui informasi mengenai node tujuan, maka node antara akan meneruskan RREQ sampai node tujuan sambil membuat next hop reverse yang nantinya akan berguna sebagai jalur pesan balasan dari node tujuan.

2. Pada saat node tujuan menerima RREQ maka node tujuan akan mengirimkan RREP sebagai pesan balasan untuk pesan RREQ, RREP berisi Sequence Number dan Hop Count, Sequence Number (Nomor urut ketujuan) berguna sebagai penghindar terjadinya routing loop. Routing loop adalah suatu kondisi dimana pesan terus ditransmisikan tanpa mencapai node tujuan, sedangkan hop count gunanya untuk proses penyeleksian mengenai jalur terbaik pada protokol routing AODV. 
3. Pada saat node antara menerima RREP node antara meneruskan RREP tersebut sampai ke node sumber sambil menaikan nilai hop count per node yang dilewatinya. Jika node sumber banyak menerima RREP maka node sumber akan melakukan penyeleksian dengan cara menghitung jalur node mana yang memiliki nilai hop count terkecil, maka di indikasikan jalur tersebut merupakan jalur terbaik.

4. Pada saat proses pencarian jalur node tujuan tidak tercapai maka di indikasikan jalur tersebut terputus maka pesan RRER dikirimkan ke tetangganya. [5].

\subsection{B.A.T.M.A.N}

Routing protokol BATMAN (Better Approach to Mobile Adhoc Network) merupakan protokol routing yang bersifat proaktif yang mana cara kerjanya semua keputusan dan informasi disebarkan secara merata keseluruh node, jadi semua node yang tergabung pada protokol routing BATMAN memiliki pengetahuan mengenai informasi seluruh node yang tergabung di dalam satu jaringan protokol routing BATMAN. Jika terjadi maintenance atau gangguan pada jaringan protokol routing BATMAN akan cepat melakukan update informasi secara berkala.

Pesan yang digunakan pada protokol routing BATMAN disebut sebagai OGM (Originator Message), OGM digunakan untuk mengetahui eksistensi mengenai node tetangga.

a. Proses pencarian jalur pada routing protokol BATMAN dengan cara mengirimkan pesan OGM secara broadcast ke node tetangganya, routing protokol BATMAN akan berusaha meminimalkan update node dengan hanya mengkalkulasikan next hop.

b. Pada saat OGM diterima oleh node tetangga, maka node tetangga kembali mengirimkan OGM ketetangganya proses ini terus berulang sampai ke node tujuan.

c. Penyeleksian jalur terbaik pada protokol routing BATMAN dengan cara melakukan perankingan, perankingan dilakukan dengan perhitungan sederhana yaitu total OGM yang telah diterima atau dikirimkan, node tetangga mana yang banyak menerima OGM atau menyebarkan OGM terbanyak, maka jalur yang melewati node ini merupakan jalur terbaik pada routing protokol BATMAN. [3].

\subsection{Delay}

Delay yang di maksud adalah End-to-End Delay (E2D), yang dihitung berdasarkan rata-rata delay antara waktu paket diterima dan saat paket dikirim. Delay sederhananya dapat di artikan sebagai waktu paket sampai ke node tujuan dari saat paket data dikirimkan, tingginya nilai delay dapat menghambat proses komunikasi antara node pengirim dan node tujuan. End-to-End Delay menggunakan persamaan berikut, yaitu treceived [i] adalah waktu saat penerimaan paket dengan urutan / id ke-i, tsent[i] adalah waktu saat pengiriman paket dengan urutan / id ke-i, dan sent adalah banyaknya paket data yang dikirimkan.

$$
\text { Average Delay: } \sum^{i=0} \frac{\text { treceived }[i]-t \operatorname{sent}[i]}{n m+}
$$

\section{METODOLOGI PENELITIAN}

Metodologi dan langkah-langkah (prosedur) yang dilakukan dalam proses penelitian berikut:

a. Studi literatur yaitu mengumpulkan data dan bahan penulisan berdasarkan data teoristis. Data yang didapatkan dari buku-buku, jurnal atau pun bahan dari internet mengenai algoritma protokol routing AODV, B.A.T.M.A.N, dan Ad-hoc Network.

b. Dalam perancangan menggunakan skenario sehingga akan didapatkan data yang sesuai dengan penelitian, skenario yang biasa digunakan untuk menguji routing di jaringan MANET adalah skenario kepadatan area atau dencity. Skenario itu dipilih mengingat kebutuhan pada jaringan MANET menggunakan kepadatan node pada area tertentu. Kemudian untuk pengujian lainya mengingat jenis routing AODV dan B.A.T.M.A.N 
(C2020 Ilmu Komputer Unila Publishing Network all rights reserved

memiliki cara kerja yang saling berbeda sehingga ditambahkan dengan skenario koneksi dan kecepatan node. Kondisi parameter skenario dalam simulasi sebagai berikut :

Tabel 1. Simulasi Parameter

\begin{tabular}{|l|l|}
\hline Routing Protocol & AODV dan B.A.T.M.A.N \\
\hline Jumlah Node & 25,50 , dan 100 \\
\hline Jumlah Koneksi & 1,2, dan 3 \\
\hline Ukuran Packet Data & $2 \mathrm{MB}$ \\
\hline Jenis Skenario & Mobility Scenario \\
\hline Jenis Mobilitas & Random Way Point \\
\hline Jenis Trafik Data & UDP \\
\hline Luas Area Jaringan & $500 x 500 \mathrm{~m}$ \\
\hline Kecepatan Node & $20 \mathrm{~m} / \mathrm{s}$ dan $50 \mathrm{~m} / \mathrm{s}$ \\
\hline Waktu Simulasi & $28800 \mathrm{~s}$ \\
\hline
\end{tabular}

c. Pembangunan simulasi kemudian dilakukan pengumpulan data simulasi jaringan ad-hoc MANET dengan menggunakan simulator OMNET++.

d. Dalam tahap analisis data simulasi, hasil yang didapatkan berdasarkan proses simulasi akan di analisis dengan menggunakan analisis statitik anova dan manova. Analisis statistika dengan menggunakan perangkat lunak excel dengan Real Statistics Resource Pack, IBM SPSS 25 dan Unscrumbler X.

\section{HASIL DAN PEMBAHASAN}

\subsection{Skenario Pengujian}

Simulator yang digunakan pada penelitian ini yaitu OMNET++ sesuai modul patch protokolnya. Skenario yang digunakan pada penelitian ini berdasarkan tingkat kepadatan, variasi jumlah koneksi dan kecepatan node seperti yang ditunjukan pada tabel berikut :

Tabel 2. Skenario dengan variasi jumlah koneksi, node dan kecepatan

\begin{tabular}{|c|c|c|c|}
\hline Skenario & Koneksi & Node & Kecepatan (mps) \\
\hline A1 & 1 & 25 & 20 \\
\hline A2 & 1 & 50 & 20 \\
\hline A3 & 1 & 100 & 20 \\
\hline B1 & 2 & 25 & 20 \\
\hline B2 & 2 & 50 & 20 \\
\hline B3 & 2 & 100 & 20 \\
\hline C1 & 3 & 25 & 20 \\
\hline C2 & 3 & 50 & 20 \\
\hline C3 & 3 & 100 & 20 \\
\hline D1 & 1 & 25 & 50 \\
\hline D2 & 1 & 50 & 50 \\
\hline D3 & 1 & 100 & 50 \\
\hline E1 & 2 & 25 & 50 \\
\hline E2 & 2 & 50 & 50 \\
\hline E3 & 2 & 100 & 50 \\
\hline F1 & 3 & 25 & 50 \\
\hline F2 & 3 & 50 & 50 \\
\hline F3 & 3 & 100 & 50 \\
\hline
\end{tabular}

\subsection{Hasil Simulasi}

Bentuk topologi jaringan ad-hoc tidak dapat diprediksi karena itu parameter simulasi dibuat secara random yaitu random way point. hasil dari simulasi pada posisi node, pergerakan node 
(C2020 Ilmu Komputer Unila Publishing Network all rights reserved

\section{Jurnal Komputasi}

dan juga koneksi yang terjadi tidak akan sama dengan topologi yang sudah direncanakan. Berikut adalah bentuk snapshoot jaringan yang akan dibuat dengan node 25, 50 dan 100 node.

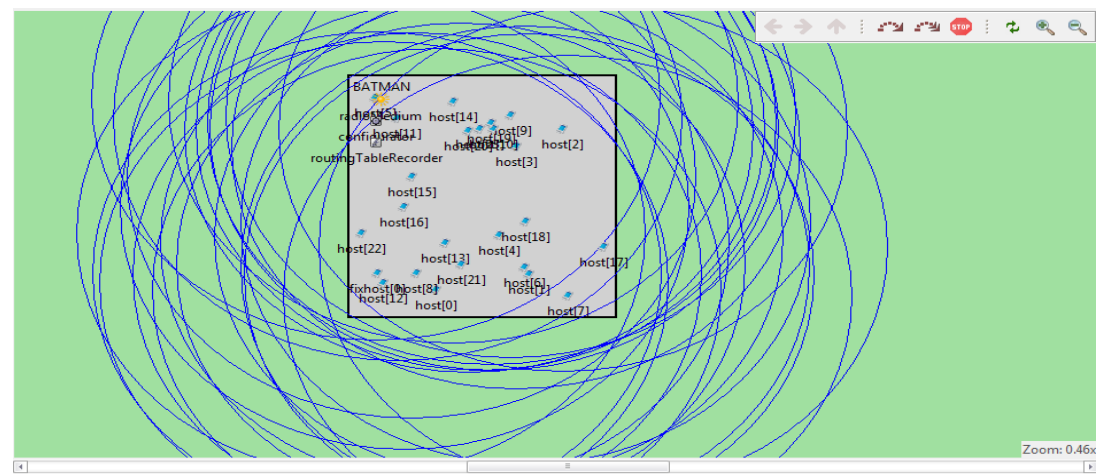

Gambar 1. Snapshoot tampilan visual jaringan dengan node 25

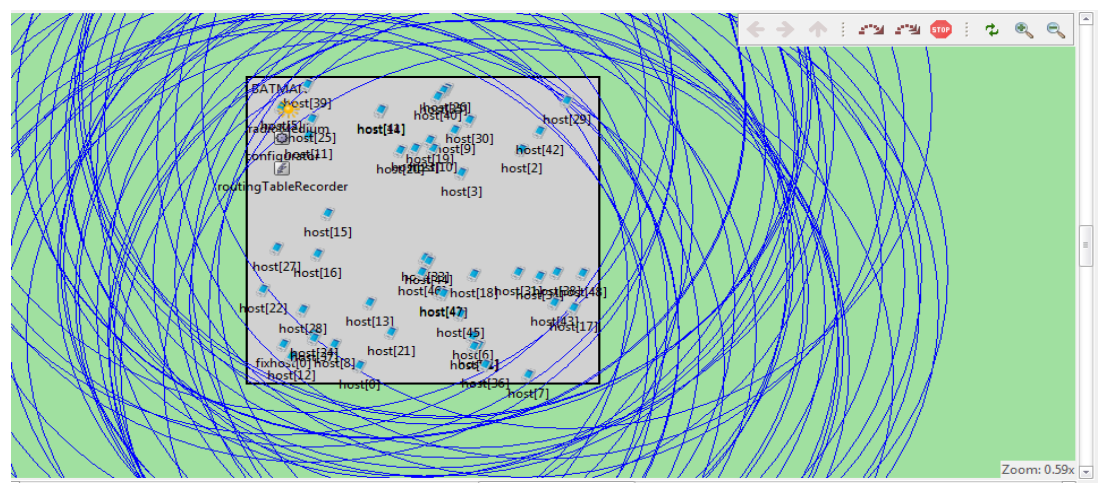

Gambar 2. Snapshoot tampilan visual jaringan dengan node 50

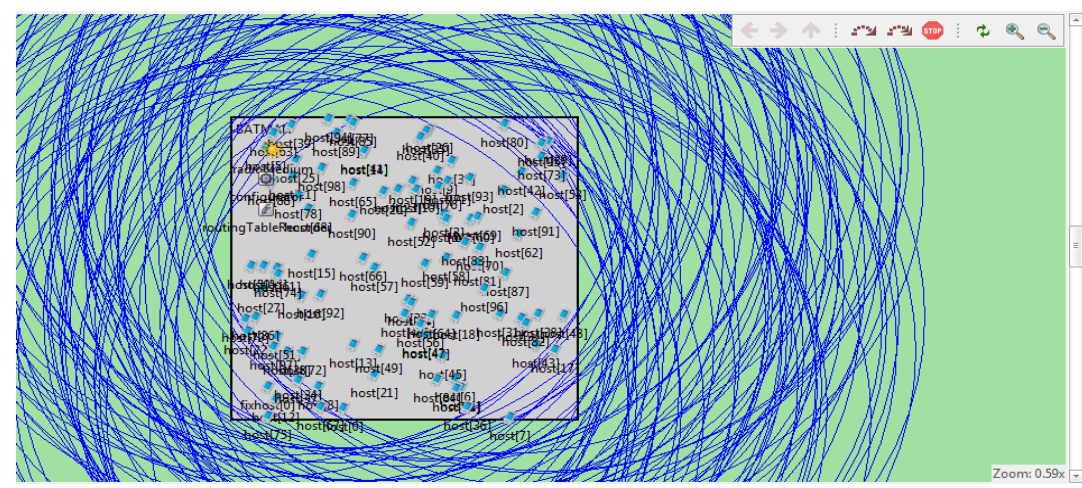

Gambar 3. Snapshoot tampilan visual jaringan dengan node 100 
Protokol routing AODV akan menjaga komunikasinya dengan melakukan proses RREQ dan RREP secara berulang- berulang selama waktu yang telah ditentukan dan jika routing protocol AODV akan melakukan update koneksi (beda node pengirim/penerima) maka routing protocol AODV akan melakukan proses tersebut berulang di mulai dari awal.

Protokol routing BATMAN, proses pengiriman paket data tersebut akan terus dilakukan oleh seluruh node sampai protokol routing B.A.T.M.A.N menemukan jalur terbaik. hal ini terjadi karena protokol routing B.A.T.M.A.N memiliki sifat pemerataan keputusan pada seluruh node. Pada saat jalur terbaik telah ditemukan maka protokol routing B.A.T.M.A.N akan melakukan komunikasi 2 arah (undirectional) dengan di tandai adanya packet UDP (User Diagram Protocol), kemudian jika telah melakukan komunikasi antara host (pengirim) dan fixhost (penerima) maka akan di tandai dengan adanya pesan ack dari si penerima (fixhost).

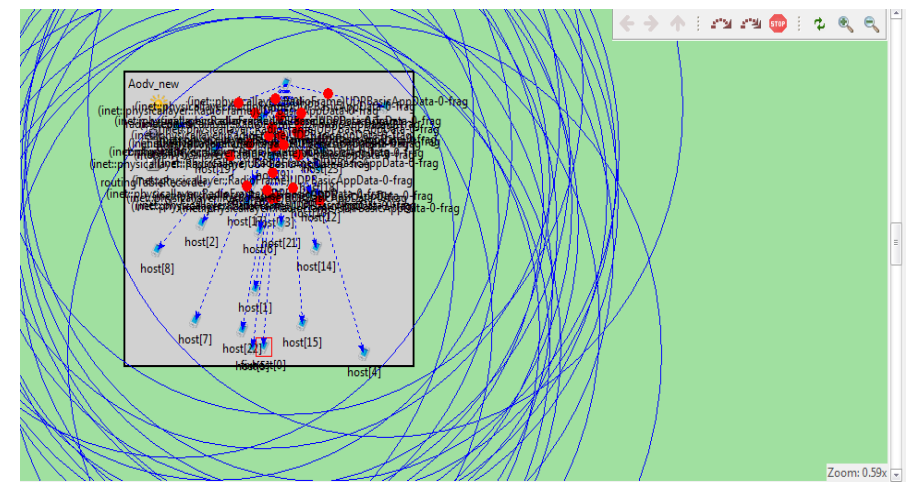

Gambar 4. Snapshoot tampilan visual jalannya data RREQ node 25 AODV

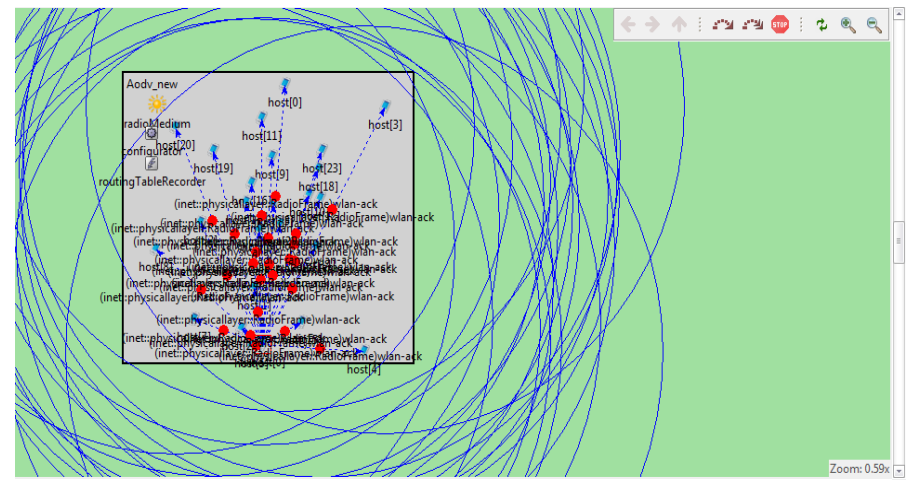

Gambar 5. Snapshoot tampilan visual jalannya data RREP node 25 AODV

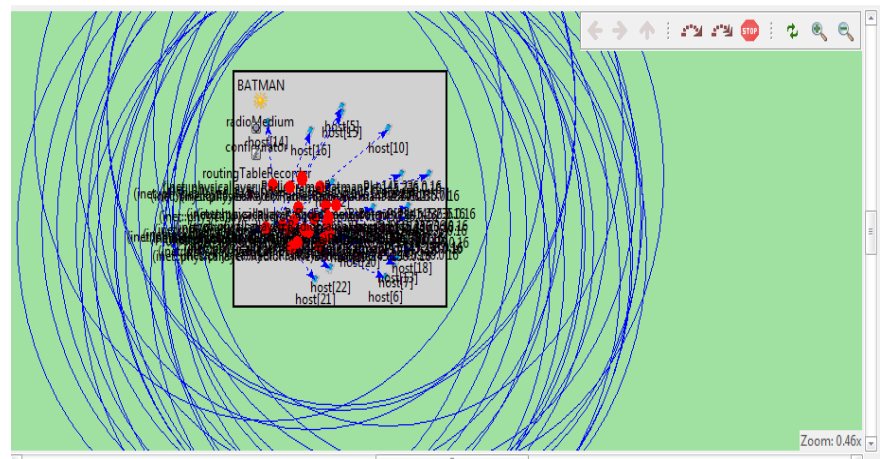

Gambar 6. Snapshoot tampilan visual jalannya packet data node 25 B.A.T.M.A.N 
(C2020 Ilmu Komputer Unila Publishing Network all rights reserved

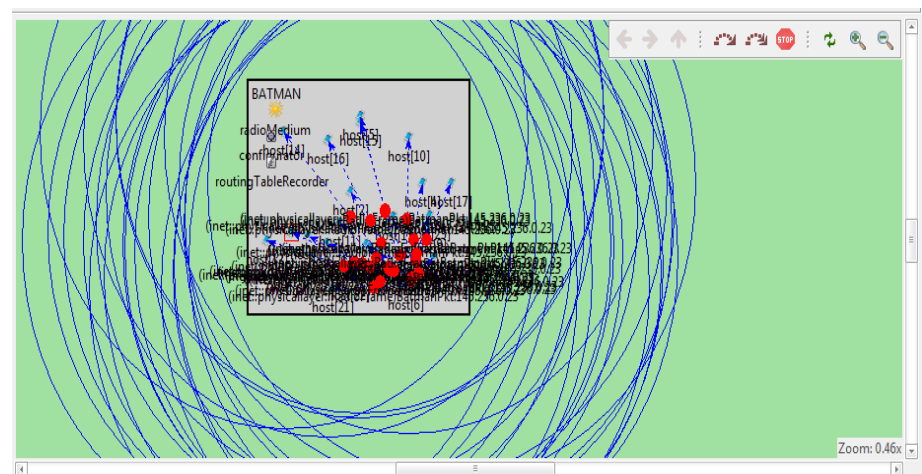

Gambar 6. Snapshoot tampilan visual jalannya packet data node 25 B.A.T.M.A.N

\subsection{Hasil Analisis}

Hasil delay protokol routing AODV dan B.A.T.M.A.N berdasarkan skenario yang menyeluruh maka akan dibandingkan nilai delay kedua routing. Adapun hasil rekap dari nilai delay dari scenario sebagai berikut :

Tabel 3. Hasil delay dengan variasi jumlah koneksi, node dan kecepatan

\begin{tabular}{|l|c|c|}
\hline SKENARIO & AODV & BATMAN \\
\hline udp 1 node 25 speed 20 & 0,00041287457750968 & 0,00022710645856790 \\
\hline udp 1 node 50 speed 20 & 0,00029654428000000 & 0,00020607783652381 \\
\hline udp 1 node 100 speed 20 & 0,00025477651100000 & 0,00001060778365238 \\
\hline udp 1 node 25 speed 50 & 0,00088777596822000 & 0,00073668816592593 \\
\hline udp 1 node 50 speed 50 & 0,00068796811129860 & 0,00057173237990000 \\
\hline udp 1 node 100 speed 50 & 0,00048968677000000 & 0,00041732379900000 \\
\hline udp 2 node 25 speed 20 & 0,00895020993650000 & 0,00631821252884620 \\
\hline udp 2 node 50 speed 20 & 0,00732126010100000 & 0,00527821964931250 \\
\hline udp 2 node 100 speed 20 & 0,00590330646725500 & 0,00474722465430000 \\
\hline udp 2 node 25 speed 50 & 0,00961037487166650 & 0,00919775763640410 \\
\hline udp 2 node 50 speed 50 & 0,00881762065000000 & 0,00863082461375000 \\
\hline udp 2 node 100 speed 50 & 0,00816783171000000 & 0,00714399879315000 \\
\hline udp 3 node 25 speed 20 & 0,03146690366666670 & 0,09079906284000000 \\
\hline udp 3 node 50 speed 20 & 0,02940662886666670 & 0,08789744543000000 \\
\hline udp 3 node 100 speed 20 & 0,02458664000000000 & 0,08027442148333330 \\
\hline udp 3 node 25 speed 50 & 0,03514108533333330 & 0,10175456956666700 \\
\hline udp 3 node 50 speed 50 & 0,03336923100000000 & 0,09037754300000000 \\
\hline udp 3 node 100 speed 50 & 0,02388169616666670 & 0,07872110000000000 \\
\hline
\end{tabular}


Delay (s)

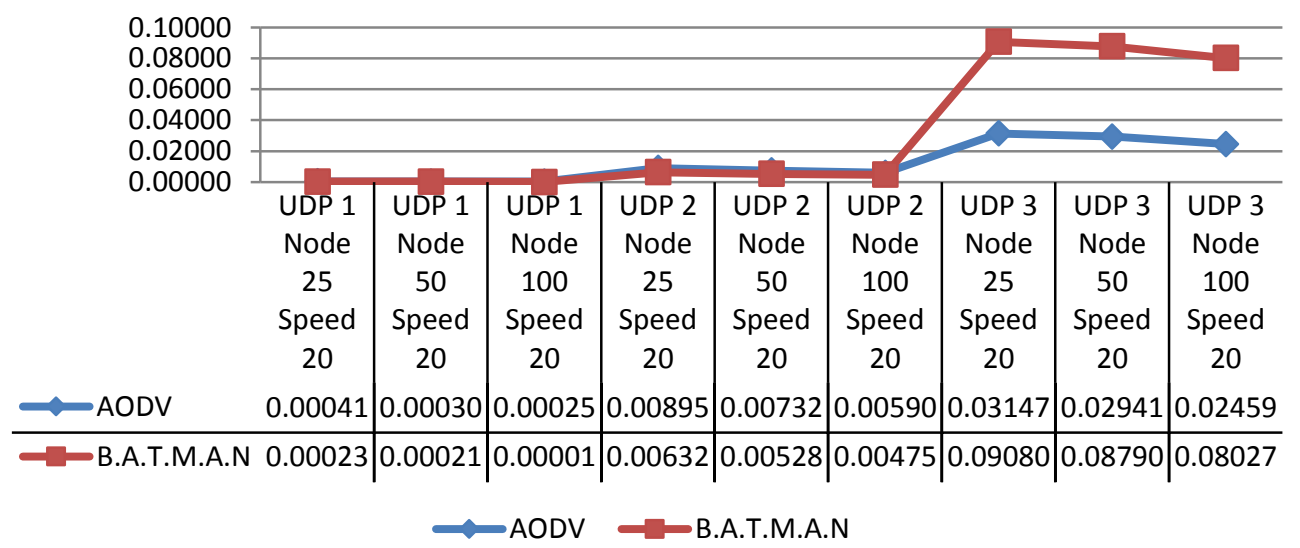

Gambar 7. grafik hasil delay pada protokol routing AODV dan BATMAN

Berdasarkan hasil delay terlihat variasi data yang didapat antara protokol AODV dan BATMAN meningkat, dan terlihat jelas pada grafik.

Memperkuat analisis dari data hasil simulasi maka dilakukan analisis statistik dari data tersebut yaitu dengan analisis multivariat, untuk mengetahui efek scenario terhadap hasil delay pada protokol AODV dan BATMAN. Multivariat dengan 2 faktor dan Partial Least Square, dengan variant $\mathrm{Y}$ adalah seluruh hasil delay yang dipetakan perfaktor parameter skenario, yaitu jumlah koneksi, jumlah node dan kecepatan node.

Tabel 4. Hasil delay dengan variasi jumlah koneksi sebagai parameter utama

\begin{tabular}{|l|l|l|l|}
\hline \multicolumn{2}{|c|}{ Threatment } & AODV & BATMAN \\
\hline \multirow{4}{*}{ UDP 1 } & node 25 speed 20 & 0,00041287457750968 & 0,00022710645856790 \\
\cline { 2 - 4 } & node 50 speed 20 & 0,00029654428000000 & 0,00020607783652381 \\
\cline { 2 - 4 } & node 100 speed 20 & 0,00025477651100000 & 0,00001060778365238 \\
\cline { 2 - 4 } & node 25 speed 50 & 0,00088777596822000 & 0,00073668816592593 \\
\cline { 2 - 4 } & node 50 speed 50 & 0,00068796811129860 & 0,00057173237990000 \\
\cline { 2 - 4 } & node 100 speed 50 & 0,00048968677000000 & 0,00041732379900000 \\
\hline \multirow{4}{*}{ UDP 2 } & node 25 speed 20 & 0,00895020993650000 & 0,00631821252884620 \\
\cline { 2 - 4 } & node 50 speed 20 & 0,00732126010100000 & 0,00527821964931250 \\
\cline { 2 - 4 } & node 100 speed 20 & 0,00590330646725500 & 0,00474722465430000 \\
\cline { 2 - 4 } & node 25 speed 50 & 0,00961037487166650 & 0,00919775763640410 \\
\cline { 2 - 4 } & node 50 speed 50 & 0,00881762065000000 & 0,00863082461375000 \\
\hline \multirow{4}{*}{ UDP 3 300 speed 50 } & 0,00816783171000000 & 0,00714399879315000 \\
\cline { 2 - 4 } & node 25 speed 20 & 0,03146690366666670 & 0,09079906284000000 \\
\cline { 2 - 4 } & node 50 speed 20 & 0,02940662886666670 & 0,08789744543000000 \\
\cline { 2 - 4 } & node 100 speed 20 5 speed 50 & 0,02458664000000000 & 0,08027442148333330 \\
\cline { 2 - 4 } & node 50 speed 50 & 0,03514108533333330 & 0,10175456956666700 \\
\cline { 2 - 4 } & node 100 speed 50 & 0,02388169616666670 & 0,07872110000000000 \\
\hline
\end{tabular}


(C2020 Ilmu Komputer Unila Publishing Network all rights reserved

Tabel 5. Hasil delay dengan variasi jumlah node sebagai parameter utama

\begin{tabular}{|c|c|c|c|}
\hline \multicolumn{2}{|c|}{ Threatment } & AODV & BATMAN \\
\hline \multirow{6}{*}{ node 25} & udp 1 speed 20 & 0,00041287457750968 & 0,00022710645856790 \\
\hline & udp 1 speed 50 & 0,00088777596822000 & 0,00073668816592593 \\
\hline & udp 2 speed 20 & 0,00895020993650000 & 0,00631821252884620 \\
\hline & udp 2 speed 50 & 0,00961037487166650 & 0,00919775763640410 \\
\hline & udp 3 speed 20 & 0,03146690366666670 & 0,09079906284000000 \\
\hline & udp ? & 0,03514108533333330 & 0,10175456956666700 \\
\hline \multirow{6}{*}{ node 50} & udp 1 & 0,00029654428000000 & 0,00020607783652381 \\
\hline & udp 1 speed 50 & 0,00068796811129860 & 0,00057173237990000 \\
\hline & udp 2 : & 0,00732126010100000 & 0,00527821964931250 \\
\hline & udp 2 speed 50 & 0,00881762065000000 & 0,00863082461375000 \\
\hline & udp 3 speed 20 & 0,02940662886666670 & 0,08789744543000000 \\
\hline & udp & 0,03336923100000000 & 300000000 \\
\hline \multirow{6}{*}{ node 100} & udp 1 speed 20 & 0,00025477651100000 & 0,00001060778365238 \\
\hline & udp 1 speed 50 & 0,00048968677000000 & 0,00041732379900000 \\
\hline & udp 2 speed 20 & 0,00590330646725500 & 0,00474722465430000 \\
\hline & udp 2 speed 50 & 0,00816783171000000 & 0,00714399879315000 \\
\hline & udp 3 speed 20 & 0,02458664000000000 & 0,08027442148333330 \\
\hline & udp 3 speed 50 & 0,02388169616666670 & 0,07872110000000000 \\
\hline
\end{tabular}

Tabel 6. Hasil delay dengan variasi jumlah speed node sebagai parameter utama

\begin{tabular}{|l|l|l|l|}
\hline \multicolumn{2}{|c|}{ Threatment } & AODV & BATMAN \\
\hline \multirow{5}{*}{ Speed 20 } & udp 1 node 25 & 0,00041287457750968 & 0,00022710645856790 \\
\cline { 2 - 4 } & udp 1 node 50 & 0,00029654428000000 & 0,00020607783652381 \\
\cline { 2 - 4 } & udp 1 node 100 & 0,00025477651100000 & 0,00001060778365238 \\
\cline { 2 - 4 } & udp 2 node 25 & 0,00895020993650000 & 0,00631821252884620 \\
\cline { 2 - 4 } & udp 2 node 50 & 0,00732126010100000 & 0,00527821964931250 \\
\cline { 2 - 4 } & udp 2 node 100 & 0,00590330646725500 & 0,00474722465430000 \\
\cline { 2 - 4 } & udp 3 node 25 & 0,03146690366666670 & 0,09079906284000000 \\
\cline { 2 - 4 } & udp 3 node 50 & 0,02940662886666670 & 0,08789744543000000 \\
\cline { 2 - 4 } & udp 3 node 100 & 0,02458664000000000 & 0,08027442148333330 \\
\hline & udp 1 node 25 & 0,00088777596822000 & 0,00073668816592593 \\
\cline { 2 - 4 } Speed 50 1 node 50 & 0,00068796811129860 & 0,00057173237990000 \\
\cline { 2 - 4 } & udp 1 node 100 & 0,00048968677000000 & 0,00041732379900000 \\
\cline { 2 - 4 } & udp 2 node 25 & 0,00961037487166650 & 0,00919775763640410 \\
\cline { 2 - 4 } & udp 2 node 50 & 0,00881762065000000 & 0,00863082461375000 \\
\cline { 2 - 4 } & udp 2 node 100 & 0,00816783171000000 & 0,00714399879315000 \\
\cline { 2 - 4 } & udp 3 node 25 & 0,03514108533333330 & 0,10175456956666700 \\
\cline { 2 - 4 } & udp 3 node 50 & 0,0333692310000000 & 0,09037754300000000 \\
\cline { 2 - 4 } & udp 3 node 100 & 0,02388169616666670 & 0,07872110000000000 \\
\hline
\end{tabular}




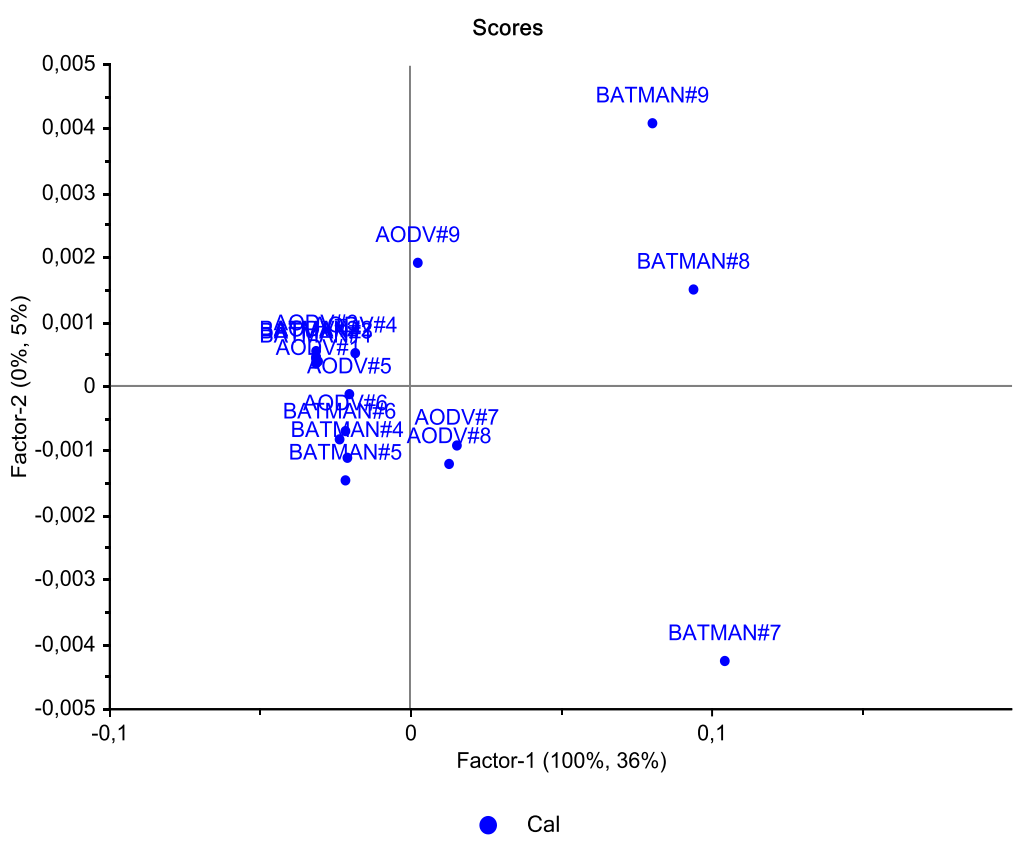

Gambar 8. Pesebaran kuadran multivariat delay pada protokol routing AODV dan BATMAN

Berdasarkan mutivariat, dampak skenario terhadap delay bahwa sangat berpengaruh pada protokol routing BATMAN, dibandingkan pada AODV. Berdasarkan pesebaran data pada kuadran,beberapa data BATMAN menjauh. Data AODV pun ada yg menjauh meskipun tidak signifikan.

Untuk lebih detil masing-masing faktor utamanya di jelaskan pada gambar berikut :
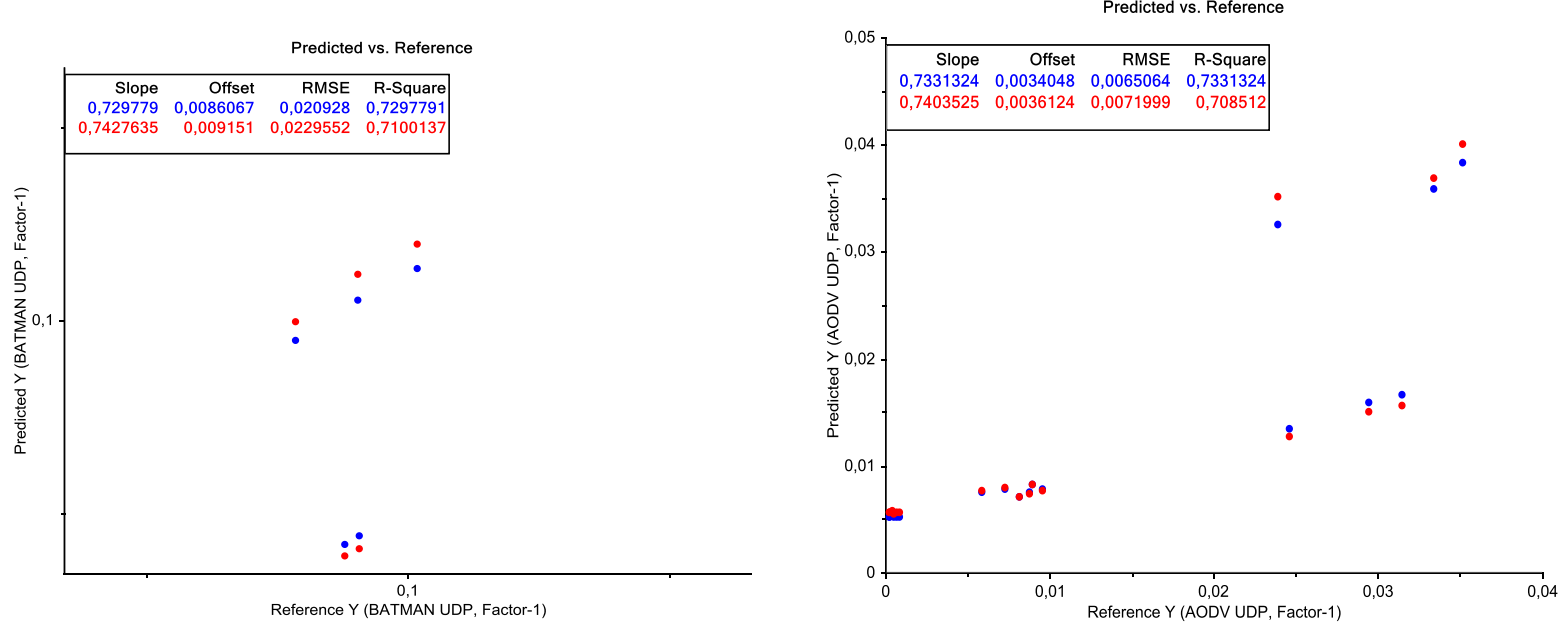

Gambar 9. Pesebaran delay faktor skenario jumlah koneksi 
Berdasarkan perbandingan data, pada faktor skenario jumlah koneksi, hasil delay protokol routing BATMAN dan AODV secara signifikan terpengaruh. Berdasarkan pesebaran data BATMAN dan AODV signifikan menjauh.
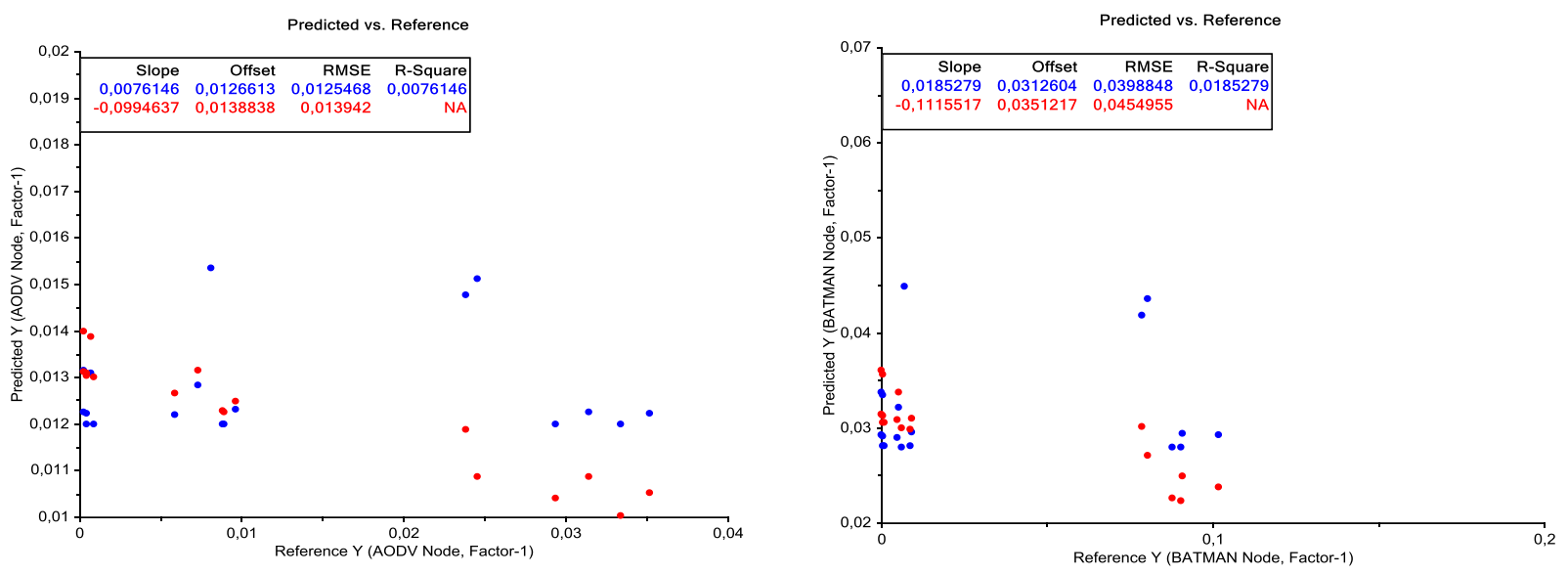

Gambar 10. Pesebaran delay faktor skenario jumlah node

Berdasarkan perbandingan data, pada faktor skenario jumlah koneksi, hasil delay protokol routing BATMAN dan AODV secara terpengaruh tetapi tidak signifikan. Berdasarkan pesebaran data BATMAN dan AODV menjauh pada jumlah node banyak.
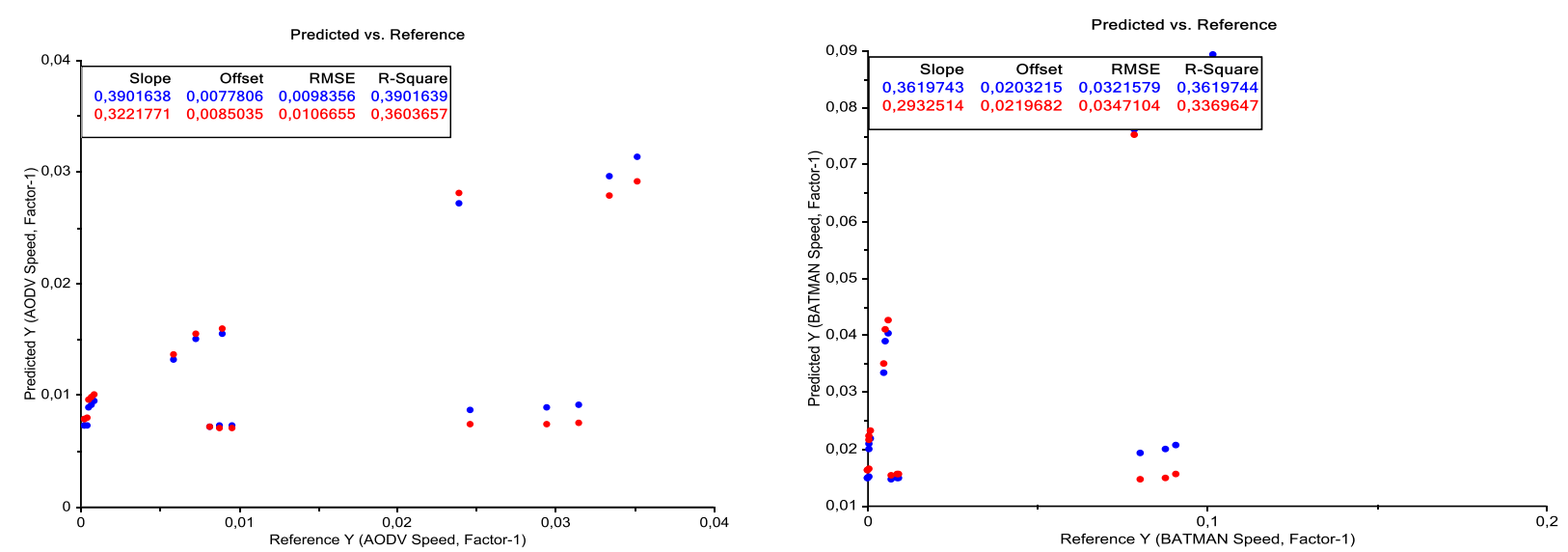

Gambar 11. Pesebaran delay faktor skenario kecepatan node

Berbanding lurus dengan analisis masing-masing faktor skenario terhadap perubahan delay dengan analisis statistika two-way anova w/o replicant pos hoc tukey, hal ini untuk mendapatkan perubahan delay yang terjadi dari variasi skenario yang diterapkan.

Tabel 7. Hasil analisis lanjutan faktor skenario jumlah koneksi

\section{AODV}

\begin{tabular}{cccccccc} 
Q TEST & & & & & & alpha & 0,05 \\
\hline \hline group 1 & group 2 & mean & q-stat & lower & upper & p-value & Cohen d \\
\hline UDP 1 & UDP 2 & 0,007623496 & 7,766847183 & 0,003818 & 0,011429 & 0,00070154 & 3,170802 \\
UDP 1 & UDP 3 & 0,029137093 & 29,68498209 & 0,025332 & 0,032943 & $3,8838 \mathrm{E}-09$ & 12,11884 \\
UDP 2 & UDP 3 & 0,021513597 & 21,91813491 & 0,017708 & 0,025319 & $6,975 \mathrm{E}-08$ & 8,948041 \\
\hline
\end{tabular}


(C2020 Ilmu Komputer Unila Publishing Network all rights reserved

\section{BATMAN}

\begin{tabular}{cccccccc} 
Q TEST & & & & & alpha & 0,05 \\
\hline \hline group 1 & group 2 & mean & $q$-stat & lower & upper & p-value & Cohen d \\
\hline UDP 1 & UDP 2 & 0,00652445 & 3,539908055 & $-0,00062$ & 0,01367 & 0,07367014 & 1,445161 \\
UDP 1 & UDP 3 & 0,087942434 & 47,71407859 & 0,080797 & 0,095088 & $2,3505 \mathrm{E}-11$ & 19,47919 \\
UDP 2 & UDP 3 & 0,081417984 & 44,17417054 & 0,074272 & 0,088564 & $4,6388 \mathrm{E}-11$ & 18,03403 \\
\hline
\end{tabular}

Tabel 8. Hasil analisis lanjutan faktor skenario jumlah node

\section{AODV}

\begin{tabular}{cccccccc} 
Q TEST & & & & & alpha & 0,05 \\
\hline \hline group 1 & group 2 & mean & q-stat & lower & upper & p-value & Cohen d \\
\hline node 25 & node 50 & 0,001094995 & 1,129066016 & $-0,002665$ & 0,004855 & 0,712394098 & 0,460939271 \\
node 25 & node 100 & 0,003864214 & 3,984449543 & 0,0001042 & 0,0076242 & 0,044138046 & 1,626644714 \\
node 50 & node 100 & 0,002769219 & 2,855383527 & $-0,000991$ & 0,0065292 & 0,157933698 & 1,165705443 \\
\hline
\end{tabular}

Tabel 9. Hasil analisis lanjutan faktor skenario kecepatan node

\section{AODV}

\begin{tabular}{cccccccc} 
Q TEST & & \multicolumn{1}{c}{ alpha } & \multicolumn{3}{c}{0,05} \\
\hline \hline & & & & & & \multicolumn{2}{c}{ Cohen } \\
group 1 & group 2 & mean & q-stat & lower & upper & p-value & $d$ \\
\hline speed 20 & speed 50 & 0,001383792 & 3,6496252 & 0,000147 & 0,00262 & 0,032582113 & 1,21654 \\
\hline
\end{tabular}

Hasil analisis statistika two-way anova w/o replicant pos hoc tukey, dengan memperhatikan nilai p-value dari masing-masing perubahan skenario. Maka faktor utama yang berpengaruh terhadap delay sebagai berikut penggunaan jumlah koneksi yang meningkat yaitu UDP 1, UDP 2 dan UDP 3, kemudian peningkatan jumlah node yaitu jumlah node 100, serta peningkatan kecepatan node yaitu kecepatan node 50 pada protokol routing AODV.

\section{KESIMPULAN}

Berdasarkan hasil penelitian maka diperoleh kesimpulan dari hasil pembahasan sebagai berikut:

a. Bahwa faktor yang sangat berpengaruh terhadap delay pada protokol routing AODV dan BATMAN adalah jumlah koneksi yang dilakukan. Semakin banyak koneksi maka akan meningkatkan delay dan akan berpengaruh pada performa jaringan komputer. Hal ini dapat di lihat dari pesebaran data hasil multivariat.

b. Faktor jumlah koneksi sangat berpengaruh pada protokol routing AODV dan BATMAN diperkirakan karena proses update jalur yang dilakukan oleh protokol routing AODV dan BATMAN. Update jalur dilakukan terus menerus, tetapi lebih berdampak pada protokol routing BATMAN karena proses update selalu dilakukan untuk mendapatkan jalur terbaik sebelum proses komunikasi data terjadi.

c. Bahwa faktor lain yang berpengaruh terhadap delay adalah penambahan jumlah node diatas 50 node dan penambahan jumlah kecepatan node diatas $100 \mathrm{~m} / \mathrm{s}$ pada protokol routing AODV.

\section{DAFTAR PUSTAKA}

[1] Devi, A. S., Nugroho, K \& Cahyadi, E. F,. 2017. Analisis Perbandingan Performasi Protocol Routing AODV Dan DSR Pada Mobile Ad-hoc Network (MANET). ISSN: 2579-9045 Seminar Nasional IPTEK Terapan (SENIT). 
(C2020 Ilmu Komputer Unila Publishing Network all rights reserved

[2] Jisha, G., Samuel, P,. 2011. Impact of Node Density on Node Connectivity in MANET Routing Protocols. International Conference on Advances in Computing and Communications. Springer:Verlag Berlin Heidelberg.

[3] Kulla, Elis dkk. 2013. Evaluation of a MANET Testbed for Central Bridge and V-shape Bridge Scenarios Using B.A.T.M.A.N Routing Protocol. IEEE 978-0-7695-5093-0/13 computer society: Eighth International Conference on Broadband, Wireless Computing, Communication and Applications.

[4] Mali, Baldev Ram \& N.C. Barwar. 2012. Performance of MANET Routing Protocols considering Impact of Node Density under Different Traffic Patterns. International Journal of Computer Applications (0975 - 8887) on Wireless Communication and Mobile Networks. Department of Computer Science and Engineering.

[5] Purba, D. Ulina, Rakhmadhany \& Primananda. 2018. Analisis Kinerja Protocol Ad-hoc On-Demand Distance Vector (AODV) dan Fisheye State Routing (FSR) pada Mobile Ad-hoc Network. e-ISSN:2548$964 X$ vol. 2, No.7 Universitas Brawijaya.

[6] Sharma, Aastikta, \& Gopalan, N. R,. 2013. A Comparative Study of B.A.T.M.A.N. and OLSR Routing Protocols for MANETs. ISSN 2278-3091 Vol.2, No. 5 International Journal of Advanced Trends in Computer Science and Engineering (IJATCSE).

[7] Sidharta, Yonas dan Widjaja, W. 2013. Perbandingan Unjuk Kerja Protocol ROuting Ad-hoc OnDemand Distance Vector (AODV) dan Dynamic Source Routing (DSR) Pada Jaringan MANET. Vol. 6, No. 1 Hal 83-89 Jurnal Tekhnologi Universitas Sanata Dharma. 